\title{
Sport beyond Moral Good and Evil
}

\author{
Jerzy Kosiewicz
}

Josef Pilsudski University of Physical Education in Warsaw, Poland

KEYWORDS

Sport is - and should be - an amoral phenomenon (what should not be confused with an immoral one); that is, a phenomenon which is completely independent from ethics, except of, possibly, deontological ethics which concerns professionals who have professional obligations towards their employers and other persons who are provided with and influenced by their services.

Conduct according to rules of a given sport has no moral character. It has only pragmatic character, similarly as conduct in compliance with principles of the administrative code, the civil code or the penal code. Of course, when you act in accordance with rules of sports rivalry you can additionally realize also other aims - like, for example, aesthetic, spectacular or moral ones. However, in each case rules of the game and legal norms have priority, because they are the most important regulative determinant of conduct in various societies, including variously defined human teams. The abovementioned legal and sports regulations are not moral norms. They can, however, influence moral behaviours if they are in conflict with the law or rules of the game.

From that viewpoint moral norms are exterritorial in their relation to assumptions and rules of a particular sport. Contestants and people responsible for them - like, for example, coaches or sports officials - as well as their employers are neither required to account for their moral beliefs, nor for their moral behaviours, if only they act in compliance with rules of sports rivalry.

sport, morality, good, evil

Within the field of social and humane considerations concerning sport it is possible to distinguish ethics dealing with that sphere of human cultural activity - that is, the ethics of sport. And within the abovementioned ethics it is possible to distinguish normative ethics, descriptive ethics and the metaethics of sport (metamorality or the philosophy of morality in its narrow sense). The presented reflections do not have normative character (they do not constitute - shortly speaking - moral values and postulates). Nor they describe possible or real ethical norms and relations included in sport. What they emphasise is, first of all, sense, essence, understanding (definition) and identity of sport in the context of moral postulates. Hence the argument pointing out that sport can be situated beyond moral good and evil, which is included in the considerations below, has strictly metaethical character and, in a deliberately controversial way, it aims at determining the identity of sport as such, and the identity of particular sports, in a fuller way.

In considerations on the place of the fair play principle among other values of sport it is possible to distinguish at least five standpoints: a) the one absolutising its qualities, b) the one pointing out that the significance of the discussed principle is still considerable but diminishing, c) the one recognising 
it as an out-of-date principle, which still, however, deserves some attention, d) the one describing it as an anachronistic Don Quixote's legacy inherited from Coubertin and the $19^{\text {th }}$ century, e) the one which completely rejects existence (need of existence) of moral principles in sport, including the fair play principle.

The view assuming that the fair play principle is the highest value in sport is characteristic for the majority of Polish theoreticians and practitioners connected with sport and with physical culture as such. It refers to, among others, Z. Żukowska, who emphasizes also pedagogical functions of the abovementioned culture. R. Żukowski, on the other hand, argues that the fair play principle is the highest value in Olympism.

The second, less absolutist standpoint is presented by some authors from countries of MiddleEastern Europe - like, for example, L. Donskis who is of an opinion that "the world of sports is simply based on Fair Play" (2005, p. 5). That viewpoint is shared by some proponents of the European Fair Play Movement, such as J. Palm, who points out that "the idea of Fair Play has the important role in Sport for All" (2004, p. 1), and who insists that "Sport for All presents a major task for the Fair Play movement" (ibid.). H. Digiel is of an opinion that "the principle of Fair Play is still valid" (2004, p. 7).

The third viewpoint is associated with S. Loland's statements, which point out to historical determinants and somehow anachronistic traits of the fair play principle - emphasizes, however that it is something more than an outmoded gentleman and Coubertin's ideal and that it can "prove its status as something more than a historical anachronism: as topical ideal” (Loland 2002, p. 102). By the way, he was clearly surprised by the fact that the discussed principle is regarded in some countries as the highest value in sport. An exchange of opinions on that topic took place during my stay as a visiting professor in the Norwegian School of Sport Sciences in Oslo in September 2009.

Digiel and Loland are not alone in their view that the fair play principle plays an important role in contemporary sport, but in English-language literature the predominant role is played by the fourth standpoint, proclaiming that the discussed principle is too archaic in its relation to assumptions of contemporary highly competitive sport and that it is Don Quixote's legacy - that is, a manifestation of noble and utopian naivety (Donskis 2005, pp. 4-5). R. Renson points out after L. Allison (2001) that upholding to the fair play principle in sport has become a manifestation of "an anachronistic survival of the amateur sport ideal" (Renson 2005, p. 3).

I would like to emphasise - and I represent the fifth of the abovementioned standpoints - that, similarly as many others, I not only do not share an opinion, and the connected arguments, that the fair play principle is the highest value in sport (it has never been it and it will never be) ${ }^{1}$. I am even of an opinion that it is quite redundant, that the basis for activity which is connected with it are rules of particular sports and not moral principles, because the latter are not connected with sport in an organic, essential and identity-related way.

Firstly, it is because of the fact that moral principles do not constitute a part of rules of particular sports, which have legal character. The discussed rules, if they are to be a basis for athletes' activities in particular sports organisations, are approved and registered by proper authorities of administrative courts. Legislation creates neither moral norms, nor customs. Law, morality and customs characteristic for various social groups, while enforcing observance of the connected norms, use sanctions which are autonomous from each other. Of course morality and customs can be sources of legal norms, similarly as law can influence ethical attitudes or customary norms. However law in the formal sense is not connected with them - that is, it neither creates moral or customary norms, nor it evaluates moral or customary behaviours (except for those which are in contradiction with it). It is

\footnotetext{
${ }^{1}$ That viewpoint and proper argumentation are presented by me more extensively in the paper "Is the Principle of Fair Play The Highest Value in Sport? - New Considerations" (Kosiewicz 2005, pp. 363-370). Nota bene, a scientific - and, especially, a philosophic - opinion is treated by me as a whole composed of content-related assumptions and a context of justification, which explains those assumptions by presenting proper reasoning. Hence, I do not give additional information that an opinion of such a kind includes arguments.
} 
obvious that commonplace interpretations of law can have moral or customs-related character. Law does not forbid such activity. It is permissible, but it is connected with law neither in an organic, nor in an essential, nor in an identity-related way. There is no organic cohesion between law and morality, because the latter (similarly as customs) is connected with the first neither in an ontological way (because morality is an abstract being of emotional and irrational character), nor it is connected with law in a functional way (because the foundation of law is morality). It means that it does not belong to the system of law, which is interpreted by L. von Bertalanffy as a rational structure (Bertalanffy 1973). The abovementioned argument concerns also statements with the included contexts of justification, referring to allegedly close connections between sport, on the one hand, and morality and customs characteristic for sportspersons milieu, on the other hand

The abovementioned essence of a given sport is constituted by two its basic components. The first of them are those qualities which - referring to Plato's theory of ideas - are general enough to be recognized as characteristic for all sports, for sport as such. The second are those qualities which make a particular sport different from the other sports. They are determined by a definition of a given sport, which is constituted, first of all, by regulations and rules of play and competition which are characteristic for a given sport. In rules of play and sports competition (influencing the contents of the second part of a given sport) there are no moral norms which would be present there in an open, clear and explicit way. They are absent also from the first component - similarly as in Plato's conception of eternal ideas. It is because of the fact that morality is included in the idea of the good, which is autonomous in its relation to others. The human being perceives it in an intuitive way and he can saturates ethics with any manifestations of his own activity. It does not mean, however, that the idea of the good is a part of the idea of the beauty or the idea of the tree.

Law (including rules of given sports, which are sanctioned by law) has not emotional and irrational qualities. Hence, in the formal (logical, methodological) sense it has different qualities than normative ethics.

On the other hand, identity of a particular sport results, first of all - and shortly speaking - from its recorded regulations. It is co-constituted also by, among others (what is not important from the viewpoint of that argument), by contestants' competitions and the connected technical and tactical assumptions, which are necessary for realization of the assumed scenario of competition (the plan of a game), not to mention architecture of sports facilities, sports equipment, sportswear and particular audience.

In my paper „Is the Principle of Fair Play the Highest Value in Sport?”, which I read in Vienna, during a conference organized by the European Fair Play Movement, and in Durham, during a conference of the British Philosophy of Sport Association (I participated both as a keynote speaker in 2004), I attempted to explain why - according to my opinion - the abovementioned principle is not the highest value in both variously defined highly competitive sport and different forms of sport of all. I presented also changes in my standpoint in that respect. First I argued that the highest value in sport is variously conceived success and then that the human being is the main basis and the most important aim of various activities connected with sport, as well as that $\mathrm{s} / \mathrm{he}$ crowns the hierarchies of immanent values determining the source, sense, essence and identity of sport. In that particularly anthropologised conception of sport I perceived also the role played - although not in the foreground - by moral influences, by the fair play principle.

In that place, on the other hand, I present another viewpoint concerning fair play, because I undermine not only axionormative views and aspirations of proponents of promotion and consolidation of the discussed principle but also the sense and the need of existence of the ethics of sport. I have come to a conclusion that sport is - and should be - an amoral phenomenon (what should not be confused with an immoral one); that is, it is completely independent from ethics, except of deontological ethics concerning professionals who have moral obligations to their employers and other persons whom they provide with their services and who are concerned by them. The abovementioned 
deontological ethics is, however, placed by me beyond the range of the notion of sport, because I am of an opinion that deontological norms - that is, moral assumptions connected with the profession of an athlete, should not be placed among identity-related qualities of a given sport at all. The more so, they should not be placed higher than those qualities, which are determined to the greatest degree by rules and regulations of play and competition which are attributed to a given sport. (Kosiewicz 2005, pp. 367-369). Admittedly deontological values are treated as moral duties, which are integrated with the professional athlete's ethos, but - from the viewpoint of methodology, formal logic and metaaxiology - it is a case of mistaken implementation, because the abovementioned values are not present in regulations of any sport, and they are not permitted by the abovementioned regulations (which expose the essence, sense and identity of particular sports). Because of that reason, in the strictly formal sense, they are situated not even in the margin of sport, but out of it. They are, in the ontological sense, external and alien, in spite of the fact that they can play an important role in - more or less emotional - relations between an employer and an employee.

In regulations of particular sports, like in the case of $\mathrm{F} 1$ car races, there can appear norms forbidding definite behaviours which are harmful for contestants' health or dangerous for their life. That kind of norms has, however, a legal - that is, strictly formal - character , and it is approved by a registering court on the basis of the Administrative Code. For example, protection of citizens' health and security from murders, temporary or permanent injuries is also legally regulated. It is not a manifestation of moral activity, because moral behaviours have solely relative and irrational character, which is in contradiction with the logic of law. Moral or customs-related implications derived from law are in contradiction with it in the methodological, logical and axiological (metaaxiological) sense, because it is impossible to derive any moral values from a strictly rational, pragmatic regulation. It is a phenomenon which is similar to that criticized by D. Hume, who proclaimed that no moral duties result from a description of reality (which includes strictly cognitive statements: truth or false in the logical sense). Conduct which is contradictory with it was called by him a naturalist fallacy (Hume 1947, 1963, 1974). That argument is applicable also to moral implications derived from regulations of particular legally regulated sports. Those implications are also logically unjustified. Taking it into account, it is possible to proclaim that moral principles are utterly external and alien in their relation to sport.

Admittedly, there has been created some normative, highly idealized moral codes, but they do not take into account everyday practice - that is, sport in reality. A normative statement concerning Olympic athletes' behaviours, which - as a matter of fact - does not take into account realities of the profession which is practiced by them, can serve as an example. What is focused on in a given case is propaganda which affirms greatness, uniqueness and superiority of the Olympic Games over nonOlympic sports and other forms of physical culture. It often seems to me - especially while reading texts by Polish proponents of the fair principle and ideologues of Olympism - that the abovementioned superiority is to refer even to cultural achievements of the ancient civilization and the contemporary civilization.

The fair play principle and the connected moral principles are (from the legal viewpoint) - as I have tried to prove above - something completely external and alien in its relation to qualities of sport, because particular sports are founded not on moral principles but on appropriate regulations which have solely pragmatic character and which simultaneously are the essence and the most literal and coherent (although often extensive) definition of the presented sport. They determine identity, character, qualities and principles of play and competition. If there were not any of them, any particular sport cannot exist (Kosiewicz 2005, p. 368). If social activity which is connected with it is registered as a sports association its rules are provided with formal qualities connected with the administrative code. Disobedience to rules of rivalry and norms of that code may result not only in administrative consequences but also with penalization. Hence regulations of a given sport have pragmatic, utilitarian qualities - they are sanctioned by the law and that way they are connected with a 
given state's jurisdiction. International sport associations are registered also by various particular national register courts.

The law allow neither any moral rules based on emotional, subjective and relative judgments which would permit to act at one's own discretion - nor latitude to be included in its regulations. By the way, there is distinguished a notion of morality of the law, but it has a different non-ethical normative meaning connected with its internal properties, such as e.g. its non-contradictory character or not applying its regulations backwards (the law should not have a retrospective character).

Introduction of moral norms into sports regulations would cause deformation of both regulations and sports, and negation of their essence, sense and function. Sports competitions would transform into rivalry first of all in the field of morality. Sports aspirations and result would be of secondary significance.

Rules of a given sport allow their twofold interpretation. The first consists in coherent and unexceptional obedience to its regulations. It leads to coming into existence of an idealized - and rarely met in practice - form of competition resulting in so-called pure play. The second allows treating those rules as something which admittedly constitutes the main determinant of the course of rivalry, but which also permits their intentional or unintentional breaking or finding loopholes in them in special cases which are saddled with sanctions.

Both ways of interpreting sports regulations are in accordance with their formal meaning and they do not have - it refers also to the second case - any morally condemnable traits. Participants of competitions (it refers especially to the second interpretation) make use of binding rules in order to achieve the maximal effect, which is expected and assumed by the strategic plan of the game. It comes from that that the main aim of rivalry is not to play in a peaceful way and without fouls (Fraleigh 2003, pp. 166-176, Li-Hong Hsu 2005, pp. 6-7, Simon 2007, pp. 219-227). Nor it is idealization of regulations of a given sport from the viewpoint of so-called pure play or realization of any transcendental - in their relation towards the rules of the game - moral norms, which would not be connected with assumed and expected results of rivalry. What is important is to realize assumed aims in such a way to avoid exclusion of a contestant or his/her team from the game and not to overstep the barrier of social norms in a way which would result in temporary or permanent exclusion (in the penal sense) from the social group of athletes or from society as such.

Conduct in accordance with regulations of a given sport has no moral character - it has only a pragmatic character, similarly as conduct in accordance with principles of the administrative, civil or penal law. Of course, while acting in accordance with regulations of sports rivalry, similarly as in accordance with legal codes, it is possible to achieve other additional aims - such as, for example, aesthetic, spectacular or moral ones. In each case, however, regulations of the game and legal norms have social priority, because they are the most important regulative determinant of conduct in variously defined human groups. The abovementioned sports and legal regulations are not moral norms. They can, however, influence moral behaviours if the latter are in conflict with the law or rules of the game.

From that viewpoint, moral norms are exterritorial in their relation to assumptions and rules of a given sport. They are so alien that they are not introduced to regulations of a particular sport. Athletes or other persons who are professionally connected with highly competitive sport - such as, for example, coaches, club officials or owners - are neither required to have moral beliefs, nor to practice moral behaviours if they act in accordance with rules of sports rivalry - both in their first and their second abovementioned meaning.

Any judgments of more or less accidental behaviours taking place during sports competitions in the light of vague moral principles lead to disruption of relations and distortion of assumptions, aims and needs of sport. The source of their inspiration is not ethics but a different axiological and normative order. The European Fair Play Movement - and the connected national movements for fair play - judge athletes' moral behaviours and ethical attitudes which are not concerned by rules of 
rivalry. Thus they judge something what is completely alien in its relation to the essence and assumptions of a particular sport. After all, moral judgments of behaviours may arise various doubts because of assumed viewpoints. The latter depend on, among others, the cultural, the ideological, the political, the religious, the historical or the geographical context. The moral judgment is determined also by personal and social experience. It is based on relativistic and situationistic motivations and needs which may be experienced and justified in different and even contradictory ways. It is obvious that that type of evaluation - that is, moral evaluation - has solely non-objective, discretionary, permanently changeable character, dependent on passing circumstances and with a context of justification lacking stable criteria.

The viewpoint presented in that paragraph need not to be more developed, because there is extensive literature - from the field of metaethics (or, in other words, metamorality or the philosophy of morality in its narrow sense) - concerning that subject and based on ethical relativism. Further abbreviated presentation of assumptions of ethical relativism and its connections with sports normative ethics would have - in the light of philosophy - features of explanations or repetitions of textbook character (and it is just something I would like to avoid)

I can add that a moral judgment or a connected ethical interference in the course of sports phenomena before them, during them or after their end seems to be - from the viewpoint of philosophy - an obvious mistake both in axionormative and cognitive sense, because it does not contribute with universalistic values deserving being universally followed. It introduces into the rules of competition and play emotional and relative moral norms, which are alien and external in its relation to pragmatic and formal assumptions.

Moreover, an attempt at subordination of sports competitions to one and, moreover, general moral norm - which can be variously interpreted and specified depending on relativistically and situationistically (referred to accidental situations) founded intuition of the good - leads to deformation of the sense and the aim of activity: especially in broadly understood highly competitive sport. Such a behaviour (which earlier had individual character) should not be rewarded, because resulting possible repetitiveness might negatively influence - as a possible categorical quasiimperative - the course of sports rivalry. It might result in priority of morality over the pragmatic determinant of the ethos, the utilitarian thread of rivalry. Such a possibility is connected with popularisation of an irrational fair play principle which is promoted by authorities and members of the European Fair Play Movement, and especially by Polish promoters of the principle. That irrationality is connected with the fact that the abovementioned principle is contradictory to the essence or the sense of sport: also as a basis for a false hierarchy of values (which assumes that the fair play principle is the highest determinant and the reference point of sports rivalry).

Behaviours of a moral character may take place and appear during sports rivalry, similarly as during production of sportswear, sports equipment or facilities - such as, for example, great stadiums. However no employer, both in the first and the second case, expects from employees of definite companies (including sports clubs and athletes employed on the basis of contracts) behavioural and moralizing ethical displays while performing their duties. They are assessed only on the basis of pragmatic effects of their work. Athletes, for example, are assessed not only on the basis of final results of rivalry, which are one of the most important indications of their level of preparation (concerning, among others, their endurance and fitness), but also on the basis of realization of technical and tactical assumptions by them in a given case.

Moral issues can be taken into consideration as a possible additional factor which stimulates some athletes or their teams for more effective - or more spectacular - rivalry (game or race) or as a factor which significantly disturbs the course of rivalry. Then they are treated in an instrumental - not in an autotelic - way.

The pointed out factor has emotive qualities, similarly as other elements of that kind - which are mediated by, among others, ideology, politics, religion or ethnical determinants. However, in variously 
manifested sports rivalry, founded on particular regulations of a given sport, the main aim certainly is not to prove moral, ideological, political, ethnical or religious superiority, but to achieve variously conceived sports success.

Moral behaviours may serve as a criterion for assessment of, among others, representatives of those professions which are accompanied by deontological ethics - such as, for example, physicians, journalist, scientists, teachers or clergymen of various denominations. However, the fact what profession is practiced by them is determined by, first of all, their professional qualifications and not by their moral predispositions or a possible vocation. Those qualifications have the primary and basic character - like the final premise while determining methodological types of sciences. Ethics has a secondary character.

In the case of clergymen, such as Catholic ones, we have to do - unlike in the case of other professions - with such a situation where professional activities should closely interweave with the priest's, the monk's or the catechist's ethical attitude, as well as with his moral teaching. Because of the fact that religious service (treated by me as a specific form of profession) cannot be separated from moral beliefs and behaviours, the discussed profession can be attributed with qualities characteristic for a vocation. The term "vocation" can be also used in the case of activity of such outstanding philosophers as Socrates, Pythagoras and his proponents or Giordano Bruno (by the way, a philosophically inspired vocation do not need implicate moral imperatives) $)^{2}$.

In the case of the athlete that type of connections has accidental character. S/he is obliged only to observe regulations of rivalry and to obey recommendations of the coach or of the head of the sports club. Neither he is ordered to be a carrier of any specific moral goods, nor he is required to make himself or his team repulsive because of his obvious immorality, indecency or showing disrespect to and breaking the abiding law.

To sum up the abovementioned considerations, I would like to emphasise that - similarly as in the past - I am not of an opinion that the fair play principle is a vital or a significant value of sport. It should not be placed in any hierarchy of values which is connected with sport, because it comes from and refers to another axiological order of behaviours and the discussed principle should not be forced into a different realm of behaviours regulated by rules of a given sport.

Nor the fair play principle - that is, its application - is the basis for, a determinant of or a test of individual or collective righteousness, or a proof of active goodness in sport, because sport is neither an ethical phenomenon, nor a touchstone or a testifier of morality. Its task is realization of pragmatic

\footnotetext{
${ }^{2}$ Nota bene in the first case (I refer to the abovementioned figures) we have to do with a vocation: with a mission of both philosophical and religious character. The first aspect is confirmed by a message included in an anecdote about Pythagoras, where he proclaims that "we, the philosophers, came to that life from another life not to achieve fame or gain money, but to look for the essence of things - that is, for the very reality - in the most insidious way" (Cyceron, V, 3, 7-9; Diogenes Laertios, VIII, 8; Malingrey 1961, pp. 30-32; Domański 1996, pp. 3-4). The second aspect, on the other hand, is connected with principles of a pious and ascetic foundation of the moral ethos called Pythagorean life, which came directly from Orphics' ethical principles described in a similar way - that is, with a name of Orphic life. According to assumptions of Pythagoreans' soteriological ethics, practicing philosophy (that is, for example, mathematics or astronomy) was - very shortly speaking - a manifestation of ascetical behaviour and, simultaneously, a form of cultic activity.

In the second case we have to do with a moral vocation of strictly philosophical character, an uncompromised mission to disseminate truth. Socrates proclaimed that virtue is a good, which was identified with knowledge; that is, with wisdom as fulfilment. He devoted his life to defending his innocence - and the connected moral beliefs, which were simultaneously his own and universal - till the end of his court trial. He rejected ethical conformism for justice understood in the absolutist way (Platon 1982, pp. 227-307).

Giordano Bruno, on the other hand, appreciated first of all not moral and religious, but strictly cognitive - that is, philosophical - views concerning construction of cosmos. They assumed, among others, plurality of worlds, and especially of planetary systems similar to our solar system. Both that vision of the universe - which, nota bene, was more revolutionary than the Copernican one - as well as his conceptions of hylosoism and panpsychism, could not be accepted by the then Catholic church, which fought them with the Holy Inquisition. Bruno identified with his philosophical vocation and even facing the stake he did not reject his views, in spite of insistent persuasion (Suchodolski 1963, pp. 405-425).
} 
aims which have been assumed in it. It refers to aims which have been determined by the human being in order to fulfil one's own and social needs, expectations and dreams.

It refers to various forms of highly competitive sport and all forms of sport for all. Highly competitive, professional, Olympic and spectacular sport is one of the most difficult, hard and tiresome forms of work. It is one of the reasons why it should be free of additional and redundant moral duties, which unnecessarily complicate both preparations for and the course of rivalry ${ }^{3}$.

On the other hand, sport for all sets out cathartic, escapist, ludic, hedonistic, aesthetic, cognitive, fitness-related, relaxative, health-related or even therapeutic aims. It is not organized because of ethical needs.

It is assumed that the first form of sport has instrumental character and the second is autotelic regarding its different relation to work. However, when it is assumed that none of the abovementioned forms of highly competitive sport or sport for all is practiced for the very sport - that is, sport as such it is the viewpoint which makes us perceive every form of sport as an instrumental one, because it is treated as a means for definite and various individual and social aims.

\section{REFERENCES}

Allison, L. (2001). Amateurism in Sport: An Analysis and a Defence. London: Frank Cass.

Bertalanffy von, L. (1973). General System Theory. New York: George Braziller.

Butcher, R., Schneider, A. (2007). Fair Play as Respect for the Game. In W. J. Morgan (Ed.) Ethics in Sport. Champaign, IL: Human Kinetics.

Cyceron (2010). Rozmowy tuskulańskie (Tusculan Disputations). In Rozmowy tuskulańskie i inne pisma (Tusculan Disputations and Other Writings). Warszawa: PWN.

Digiel, H. (2004). The Principle of Fair Play - Why doping must never be allowed. Academic Supplement of Fair Play! The Official Publication of the European Fair Play Movement, 2, 6-8.

Diogenes Laertios (1982). Żywoty i poglądy stynnych filozofów (Lives and Opinions of Eminent Philosophers). Warszawa: PWN.

Domański, J. (1966). Metamorfozy pojęcia filozofii (Metamorphoses of the Notion of Philosophy). Warszawa: Polska Akademia Nauk. Instytut Filozofii i Socjologii.

Donskis, L. (2005). Fair Play and the Legacy of Don Quixote. Academic Supplement of Fair Play! The Official Publication of the European Fair Play Movement, 4, 4-5.

Fraleigh, W. (2003). Intentional Rules Violations - One More Time. Journal of the Philosophy of Sport, no. XXX.

Fraleigh, W. (2007). Intentional Rules Violations - One More Time. In W. J. Morgan (Ed.) Ethics in Sport. Champaign, IL: Human Kinetics.

Hume. D. (1947). Badania dotyczące rozumu ludzkiego (Enquiry Concerning Human Understading). Kraków: PWN.

Hume, D. (1963). Traktat o naturze ludzkiej (A Treatise of Human Nature). Warszawa: PWN.

Hume, D. (1974). Zwiazek konieczny (Necessary Connection). In S. Jedynak, Hume (1974). Warszawa: PW „Wiedza Powszechna”.

Jirasek, I. (2005). Fair play. In Filosoficka kinantropologie: setkani filosofie, ttela a pohybu. Olomouc:Vydala Univerzita Palackeho.

Kosiewicz, J. (2004). Is the Principle of Fair Play the Highest Value in Sport? Academic Supplement of Fair Play! The Official Publication of the European Fair Play Movement, 4, 9-10.

\footnotetext{
${ }^{3}$ I would like to emphasise that the majority of the arguments from the context of justification which is presented in the text aims at challenging a commonly approved thesis which affirms a need and merits of a close connection between morality and sport. If it comes from my assumption and the connected argumentation that sport can be situated beyond moral good and evil, and athletes' activity can be based on rules of definite sports, which are independent from ethics, I think that it is justified to proclaim that forcing athletes to behave according to moral principles is a redundant burden and an additional non-professional duty for them and their profession (which is somehow similar to enforced religious behaviours).
} 
Kosiewicz, J. (2005). Is the Principle of Fair Play the Highest Value in Sport? - New Considerations. In J. Kosiewicz (Ed) (2005) Sport, Culture and Society. Warsaw: AWF.

Kosiewicz, J. (2010). Physical Recreation in the Mirror of Philosophy. In J. Kosiewicz (2010). Sport and Philosophy: From Methodology to Ethics. Warsaw: Wydawnictwo BK.

Kretchmar, R. S. (2005). Ethics, Value Choices, and the Good Life. In Practical Philosophy of Sport and Physical Activity. Champaign, IL: Human Kinetics.

Li-Hong (Leo), Hsu (2005). Revisiting Fair Play: Cheating, the 'Good Foul' and Sport Rules. Academic Supplement of Fair Play! The Official Publication of the European Fair Play Movement, 4.

Loland, S. (2002). Fair play: historical anachronism or topical ideal. In M. J. McNamee, J. Perry (Eds.) Ethics \& Sport. London and New York: Spon Press. Taylor \& Francis Group.

Loland, S. (2002). Fair play in Sport: A Moral Sport System. London \& New York: Routledge.

Morgan, W. J. (2006). Why sports morally matter. New York and London: Routledge.

Malingrey, A. M. (1961). Philosophia. Etude d'un groupe de mots dans la literature grecque, des Presocratiques au IVt siecle apres J.-C. Paris.

Palm, J. (2004). Sport for All! - Fair Play for All? Academic Supplement of Fair Play! The Official Publication of the European Fair Play Movement, 1, 1-2.

Platon (1982). Obrona Sokratesa (Apology). In Uczta, Eutyfron, Obrona Sokratesa, Kriton, Fedon (Symposium, Euthyphro, Apology, Kriton, Phaedon). Warszawa: PWN.

Renson, R. (2005). Fair Play, Fair Game, Lair Game, Fair Pay: Ethics versus Rhetoric in Sport and Society. Academic Supplement of Fair Play! The Official Publication of the European Fair Play Movement, 4.

Simon, R. L. (2007). The Ethics of Strategic Fouling: A Reply to Fraleigh. In W. J. Morgan (Ed.) Ethics in Sport. Champaign, IL: Human Kinetics.

Suchodolski, B. (1963). Bruno. In Narodziny nowożytnej filozofii człowieka (Birth of Modern Philosophy of Man). Warszawa: PWN.

\section{AUTHOR'S ADDRESS:}

Jerzy Kosiewicz

Department of Philosophy, Chair of the Social Sciences Josef Pilsudski University of Physical Education in Warsaw 34 Marymoncka str., 00-968 Warsaw, Poland

Email: jerzy.kosiewicz@awf.edu.pl 